\title{
Risks of leukaemia among residents close to high voltage transmission electric lines
}

\author{
Gilles Thériault, Chung-Yi Li
}

\begin{abstract}
Objectives-To reassess the risk of leukaemia associated with residential exposure near high voltage transmission electric lines of $49 \mathrm{kV}$ and above in view of the recent publications.

Methods-Through a review of papers considering the risk of leukaemia among people living near high voltage transmission lines, the combined risks of leukaemia were calculated for distances $\leqslant 50 \mathrm{~m}$ and $\leqslant 25 \mathrm{~m}$ and for exposures at $2 \mathrm{mG}, 3$ $\mathrm{mG}, 4 \mathrm{mG}$, and $10 \mathrm{mG}$.

Results-The combined analysis of the contributive studies indicated an estimate of risk (odds ratio (OR)) for exposure $\geqslant 2$ mG of $1.3,95 \%$ confidence interval $(95 \% \mathrm{CI}) 1.0$ to 1.7 . The ORs increased with exposures at $3 \mathrm{mG}, 4 \mathrm{mG}$, and $10 \mathrm{mG}$. The risks were also increased for distances of 50 and $25 \mathrm{~m}$ from the lines.

Conclusions-This meta-analysis tends to confirm the presence of an association between exposure to magnetic fields and leukaemia among people who reside in the vicinity of high voltage transmission electric lines of $\geqslant 49 \mathrm{kV}$. There is consistency across studies. Measures of exposure used in the studies were either distance from the lines or calculated fields estimated from pertinent line features. The results apply to adults as well as to children.
\end{abstract}

(Occup Environ Med 1997;54:625-628)

Keywords: leukaemia; electromagnetic fields; cancer environmental health; meta-analysis

Department of

Occupational Health, McGill University, Montréal, Québec, Canada

G Thériault

Department of Epidemiology and Biostatistics, McGill

University, Montréal, Québec, Canada

G Thériault

C-Y Li

Correspondence to: Dr Gilles Thériault, Joint Departments of Epidemiology, Biostatistics and Occupational Health, McGill University, 1020 Pine Avenue West, Montréal, Québec H3A 1A2, Canada.

Accepted 27 May 1997
Several studies have considered the relation between residential exposure to 50 or $60 \mathrm{~Hz}$ magnetic fields and the risk of leukaemia among children and adults who live there. ${ }^{1}$ In assessing exposure, authors have used several means: wire code, spot measurements, four corner measurements, bedroom measurements, calculated exposure from circulating current in high voltage overhead power lines, and more recently personal dosimetry. ${ }^{2}$

So far, these studies have come to a paradoxical result: they found a relation between electrical wiring around the house of leukaemia cases but no such relation with magnetic fields measured directly inside the house $^{3-5}$ To explain this paradox, scientists have proposed that electrical wiring around the house may be a better marker of historical exposure to magnetic fields than direct contemporary measurements, which actually fluc- tuate continuously with daily and seasonal use of electricity.

This paradox was considered by Feychting et $a t^{t}$ from further analysis of the results of their study of people living near high voltage transmission lines. ${ }^{78}$ They proposed that the measurements that best predicted the risk of leukaemia were those estimated at time of diagnosis calculated from historical information on annual average loads on the power lines which they called the "historical annual average calculation". These calculations explain the increased risk of leukaemia among residents living near high power transmission lines better than spot measurements and they proposed that the difference between these results are attributable to the time interval between diagnosis and contemporaneous estimates of magnetic fields. ${ }^{6}$

We recently conducted a study of 870 cases of adult leukaemia in which we used both distance from high power transmission lines and historical annual average calculation to estimate exposure. ${ }^{9}$ We did find an association between risk of leukaemia and both proximity of residences to high voltage transmission lines and historical annual average calculation of exposure. Our study confirmed the finding made by Feychting et al of an association between leukaemia and magnetic fields originating from high power transmission lines and seemed to support their claim that historical annual average calculation is a better marker than spot measurements as the aetiologically relevant exposure.

In view of these recent findings, we reanalysed the studies that have considered leukaemia in people residing in the vicinity of high voltage transmission lines.

\section{Methods}

We reviewed the abundant literature on measurements of magnetic fields in residences. We selected papers that considered specifically the exposure resulting from the vicinity of houses to high voltage transmission lines of $\geqslant 49 \mathrm{kV}$ and in which exposure was expressed either as calculated magnetic fields from lines, or as distance, or both.

With the Mantel-Haenszel method for a summary odds ratio (OR) for a series of $2 \times 2$ tables, ${ }^{10}$ we calculated the combined risk ratios for leukaemia for distances of $\leqslant 50 \mathrm{~m}$ and $\leqslant 25$ $\mathrm{m}$ and for exposure at $2 \mathrm{mG}, 3 \mathrm{mG}, 4 \mathrm{mG}$, and $10 \mathrm{mG}$. For the heterogeneity test of the ORs, we used the Woolf's test for heterogeneity of two or more subgroup ORs. ${ }^{11}$ 
Table 1 Percentage of residences exposed to magnetic fields originating from high voltage transmission lines in residential studies of leukaemia

\begin{tabular}{|c|c|c|c|}
\hline \multirow[b]{2}{*}{ Studies } & \multirow[b]{2}{*}{ Distance $<50 \mathrm{~m}$} & \multicolumn{2}{|l|}{ Exposure } \\
\hline & & $\geqslant 1 m G$ & $\geqslant 2 m G$ \\
\hline \multicolumn{4}{|l|}{ Children: } \\
\hline Coleman et $a^{12}$ & 0.6 & & \\
\hline Myers et $a l^{3} \dagger$ & 5.4 & 0.7 & 0.0 \\
\hline Feychting and Ahlbom ${ }^{7}$ & 6.0 & 13.0 & 8.0 \\
\hline Olsen et al ${ }^{14}$ & & 0.4 & $0.2^{\star}$ \\
\hline Verkasalo et $a l^{15}$ & & 11.7 & 5.4 \\
\hline Tynes and Haldoren ${ }^{17}$ & 9.4 & $8.1^{\star \star}$ & $3.6^{\star \star \star}$ \\
\hline \multicolumn{4}{|l|}{ Adults: } \\
\hline Youngson et $a^{16} \neq$ & 3.4 & 0.7 & $0.3^{\star \star \star \star}$ \\
\hline Feychting and Ahlbom ${ }^{8}$ & 6.4 & 14.7 & 7.7 \\
\hline $\mathrm{Li}$ et $a l^{1}$ & 6.5 & 14.7 & 9.7 \\
\hline
\end{tabular}

$\star \geqslant 2.5 \mathrm{mG} ;{ }^{\star \star} 0.5-1.4 \mathrm{mG} ;{ }^{\star \star \star}>1.4 \mathrm{mG} ;{ }^{\star \star \star \star} \geqslant 3 \mathrm{mG} ; \dagger$ non-solid tumours; $\ddagger$ all haematological cancers.

Table 2 Leukaemia risk in residences $\leqslant 50 \mathrm{~m}$ from high voltage transmission lines

\begin{tabular}{|c|c|c|c|c|}
\hline \multirow[b]{3}{*}{ Studies } & \multicolumn{4}{|l|}{ Exposure } \\
\hline & \multicolumn{2}{|l|}{$\leqslant 50 m$} & \multicolumn{2}{|l|}{$\leqslant 25 m$} \\
\hline & OR $(95 \% C I)$ & $n$ & OR $(95 \% C I)$ & $n$ \\
\hline \multicolumn{5}{|l|}{ Children: } \\
\hline Myers et $a l^{13} \dagger$ & $1.1 \quad(0.5$ to 2.7$)$ & 11 & $1.6(0.5$ to 5.0$)$ & 7 \\
\hline Feychting and Ahlbom ${ }^{7}$ & 2.9 (1.0 to 7.3$)$ & 6 & & \\
\hline Tynes and Haldoren ${ }^{17}$ & $0.6(0.3$ to 1.3$)$ & 9 & & \\
\hline \multicolumn{5}{|l|}{ Adults: } \\
\hline Coleman et $a l^{12}$ & $2.0(0.4$ to 9.0$)$ & 3 & $2.0(0.1$ to 31.6$)$ & 1 \\
\hline Youngson et $a^{16} \ddagger$ & $1.3(1.0$ to 1.7$)$ & 137 & $1.3(0.9$ to 1.8$)$ & 77 \\
\hline Feychting and Ahlbom ${ }^{8}$ & $1.2(0.7$ to 2.0$)$ & 24 & & \\
\hline Li et $a l^{1}$ & $2.1 \quad(1.4$ to 3.0$)$ & 89 & 2.5 (1.5 to 3.9$)$ & 66 \\
\hline Combined & $1.4(1.2$ to 1.7$)$ & & $1.6(1.2$ to 2.1$)$ & \\
\hline Heterogeneity test (df) & $11.52(6)$ & & $5.69(3)$ & \\
\hline$P$ value & $>0.05$ & & $>0.10$ & \\
\hline
\end{tabular}

† Non-solid tumours; $¥$ all haematological cancers. $>100 \mathrm{~m}$ used as comparison group.

\section{Results}

There were only nine studies ${ }^{7-9}{ }^{12-17}$ that met the inclusion criteria (table 1). Also reported in the table, for each study, are the proportion of residences within $50 \mathrm{~m}$ of the lines or exposed to 1 $\mathrm{mG}$ and $2 \mathrm{mG}$. To calculate exposure estimates of magnetic fields, they used several line features - such as current loads, height of the wires, configuration of the wires, and distance between houses and the lines.

Four studies had very few subjects exposed to $\geqslant 1 \mathrm{mG}(<1 \%)$. These were the studies by Myers et al, ${ }^{13}$ Olsen et al,,$^{14}$ Youngson et al, ${ }^{16}$ and Coleman et $a l^{12}$ (Coleman et al did not use calculated magnetic fields but only distance between residences and high voltage transmission lines). The reason that these studies had such a low proportion of exposed people is that they were conducted in the general population whereas it is well known that over a whole country, very few residences are within $100 \mathrm{~m}$ of overhead high voltage transmission lines particularly in those countries where rights of ways are delineated on both sides of the transmission lines. On the other hand, the other five studies (Feychting and Ahlbom, ${ }^{7}$ Verkasalo et $a l,{ }^{15}$ Feychting and Ahlbom, ${ }^{8}$ Tynes and Haldoren, ${ }^{17}$ and $\mathrm{Li}$ et $a l^{9}$ ) were conducted either among residences within predefined corridors along high voltage transmission lines or within densely populated areas where a large proportion of the population live near overhead power lines. That explains why these studies have $12 \%$ to $15 \%$ of their residences exposed to $\geqslant 1 \mathrm{mG}$ and $5 \%$ to $10 \%>2 \mathrm{mG}$. Only these last studies carry a valuable contribution to information on the relation between exposure to magnetic fields and leukaemia, as the others have too few exposed subjects to do so.

\section{COMBINED ANALYSIS}

Table 2 shows the risk of leukaemia by proximity of residences ( $\leqslant 50$ and $\leqslant 25 \mathrm{~m}$ ) to high voltage transmission lines.

Most studies reported risks above 1.0, several had a $95 \%$ confidence interval $(95 \%$ CI) that did not include unity. A combined analysis with the Mantel-Haenszel method ${ }^{10}$ shows that the risks are significant, somewhat more so for residences $\leqslant 25 \mathrm{~m}$ (OR $1.6,95 \%$ CI 1.2 to 2.1) than for those $\leqslant 50$ metres (OR $1.4,95 \%$ CI 1.2 to 1.7 ) from the lines.

Table 3 shows the risks of leukaemia by exposure to $\geqslant 2 \mathrm{mG}$ resulting from high voltage transmission lines.

Except for the study of Tynes and Haldoren on children ${ }^{17}$ and that of Feychting and Ahlbom on adults, ${ }^{8}$ all risks are above 1.0, several of them showing a $95 \%$ CI that does not include unity. The combined analysis shows risks that are significant for exposures of 2, 3, 4, and $10 \mathrm{mG}$ compared with exposure to $\leqslant 1$ $\mathrm{mG}$. There is some increase in risk going from $2 \mathrm{mG}$ (OR $1.35,95 \%$ CI 1.05 to 1.74 ) to 10 $\mathrm{mG}$ (OR $1.81,95 \%$ CI 1.14 to 2.87 ).

\section{VALIDITY OF EXPOSURE ESTIMATES}

Some authors have discussed the validity of using exposure estimates calculated from high voltage transmission lines as a method of

Table 3 Leukaemia risks resulting from exposure to $\geqslant 2 m G$ originating from high voltage transmission lines

\begin{tabular}{|c|c|c|c|c|}
\hline \multirow[b]{2}{*}{ Studies } & \multicolumn{4}{|l|}{ Exposure } \\
\hline & $\begin{array}{l}\geq 2 m G \\
\text { OR }(95 \% C I) n\end{array}$ & $\begin{array}{l}\geqslant 3 m G \\
\text { OR }(95 \% C I) n\end{array}$ & $\begin{array}{l}\geqslant 4 m G \\
O R(95 \% C I) n\end{array}$ & $\begin{array}{l}\geqslant 10 m G \\
O R(95 \% C I) n\end{array}$ \\
\hline \multicolumn{5}{|l|}{ Children: } \\
\hline Feychting and Ahlbom 7 & $2.7(1.0$ to 6.3$) 7$ & $3.8(1.4$ to 9.3$) 7$ & & \\
\hline Olsen et al ${ }^{14}$ & $1.7^{\star}(0.3$ to 6.7$) 3$ & & $6.0(0.8$ to 44.0$) 3$ & \\
\hline $\begin{array}{l}\text { Verkasalo et } \text { al }^{5^{5}} \\
\text { Tynes and Haldoren }\end{array}$ & $\begin{array}{l}1.6(0.3 \text { to } 4.5) 3 \\
0.8^{\star \star}(0.3 \text { to } 2.4) 4\end{array}$ & & $1.2(0.3$ to 3.6$) 3$ & \\
\hline \multicolumn{5}{|l|}{ Adults: } \\
\hline $\begin{array}{l}\text { Youngson et al }{ }^{16} \neq \\
\text { Feychting and Ahlbom }\end{array}$ & $1.0+(0.7$ to 1.7$) 26$ & $1.9(0.8$ to 4.4$) 15$ & & $3.0(0.6$ to 14.9$) 6$ \\
\hline $\begin{array}{c}\text { Li et al } \\
\text { 1 }\end{array}$ & 1.4 (1.0 to 1.9$) 97$ & $1.4(1.0$ to 2.0$) 84$ & $1.4(1.0$ to 2.0$) 73$ & 1.7 (1.0 to 2.7$) 45$ \\
\hline Combined & $1.3(1.0$ to 1.7$)$ & $1.6(1.2$ to 2.2$)$ & $1.5(1.1$ to 2.2$)$ & $1.8(1.1$ to 2.9$)$ \\
\hline $\begin{array}{l}\text { Heterogeneity test (df) } \\
\text { P value }\end{array}$ & $\begin{array}{l}3.65(5) \\
>0.10\end{array}$ & $\begin{array}{l}4.19(2) \\
>0.10\end{array}$ & $\begin{array}{l}1.74(2) \\
>0.10\end{array}$ & $0.43(1)$ \\
\hline
\end{tabular}

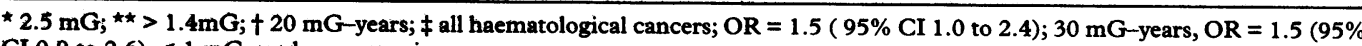
CI 0.9 to 2.6$).<1 \mathrm{mG}$ used as comparison group. 


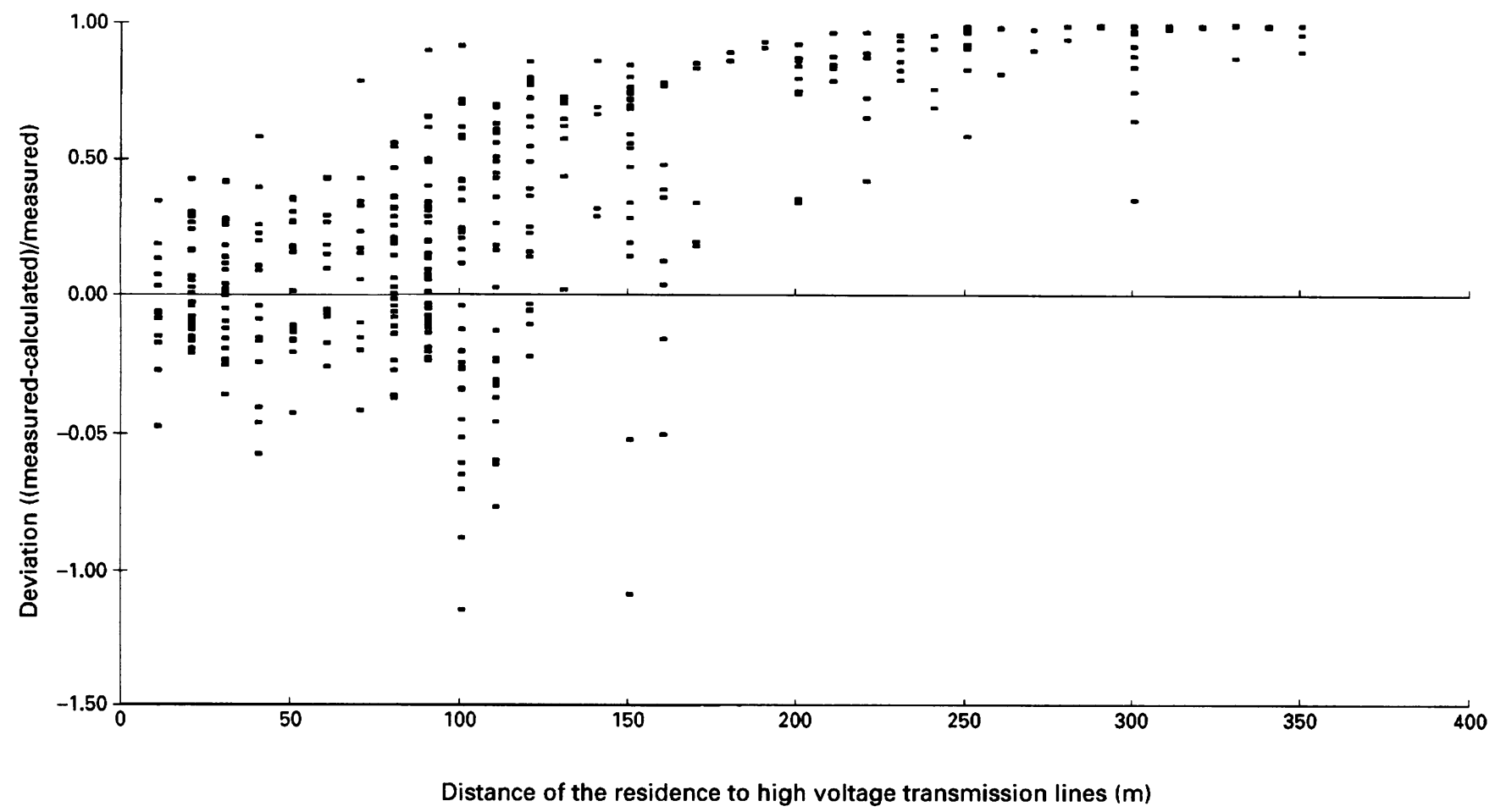

Deviation of calculated magnetic fields from measured magnetic fields in a sample of 407 houses.

assessing exposure in houses near those lines. $^{7818}$ In a recent study ${ }^{9}$ we compared exposure estimates obtained by calculation based on line with results from direct measurements in 407 residences (figure). In this figure the difference between the two exposures is expressed as the ratio of measured fields minus calculated fields/measured fields. The absence of a difference lies on the zero line.

Information can be extracted from this figure. Firstly, measured magnetic fields yield values that are usually higher than calculated magnetic fields. This is no surprise as measured magnetic fields correspond to the summation of magnetic fields generated from the high voltage transmission lines and the local magnetic fields generated in or around the house. Secondly, when distance increases, the difference between calculated and measured magnetic fields increases. This indicates that with distance the contribution to overall exposure from the local magnetic fields generated in or around the house increases and within a short distance from the line, the exposure from the line contributes to almost all the exposure inside the house. Thirdly, starting at about 90 $\mathrm{m}$, the differences between calculated and measured fields increase and beyond about 100 $\mathrm{m}$, there is poor agreement between measured and calculated exposure, the measured exposure gives higher readings than the calculated ones. It would be false to think that such people are not exposed at all; actually they are exposed like everybody else to the baseline level. For these distances, calculated values from high voltage transmission lines become useless. In summary, magnetic fields calculated from high voltage transmission lines are reliable for distances $\leqslant 50 \mathrm{~m}$ from the centre of the lines, they cannot be relied on when distance is $>100 \mathrm{~m}$, and they are of question- able value for distances between 50 and $100 \mathrm{~m}$. This corresponds to field intensities of $\geqslant 1.0$ $\mathrm{mG}(\leqslant 50 \mathrm{~m})$ and $\leqslant 0.5 \mathrm{mG}(\leqslant 100 \mathrm{~m})$ living near high voltage transmission lines. A corollary to that observation is that exposure calculated from high voltage transmission lines is a reliable marker of a true exposure within $100 \mathrm{~m}$ and that exposure in homes located near such lines is less prone to the variations encountered in residences away from the lines.

\section{Discussion}

The present comparison tends to confirm the existence of an association between exposure to electromagnetic fields and leukaemia among people who live near high voltage transmission lines. The combined risks are increased for all calculated exposures of $\geqslant 2 \mathrm{mG}$.

As it included many subjects, the study by $\mathrm{Li}$ et al strongly influenced the combined results. This calls for prudence in interpreting the combined analysis. Furthermore, metaanalyses such as the present one can only serve the goal of increasing sample size and have nothing to do with the validity of the pooled results. One valid study will contribute more to the understanding of an aetiological relation between exposure and disease than the summation or pooling of scores of weak studies. This should keep us from proclaiming that this is definitive evidence that magnetic fields from high voltage power lines cause leukaemia among residents who live near them. Nevertheless, it must be recognised that the study of $\mathrm{Li}$ et al was planned with the intention of testing the hypothesis, and it avoided the problem of few study subjects.

Our assessment of evidence is based solely on the published literature and consequently the existence of a publication bias cannot be ruled out. We included in the combined analy- 
sis all the published articles eligible for inclusion. They are a subset of a much larger set of papers, several of them reporting results of studies conducted recently to test the hypothesis of an association between magnetic fields and leukaemia in which negative findings would have been just as important as positive ones. But there remains the possibility that papers which reported negative results may have been rejected or not published, which may have entailed a bias towards finding an association that actually does not exist.

It has been common practice so far to consider children and adult studies separately. The reason for doing so is that childhood leukaemia is predominantly of the acute lymphoid type whereas adult leukaemias are mostly of the acute myeloid and chronic lymphoid type. These are regarded as separate diseases. In the present analysis, the findings apply equally to both children and adults. Analysing them separately would have yielded similar results with larger $95 \%$ CIs and greater instability in rates due to few cases in each category.

If the present comparison is correct, it indicates that contrary to widespread opinion, there is reasonable consistency between studies on the relation between exposure to magnetic fields and leukaemia when exposure is based on calculated fields from high voltage transmission lines at time of diagnosis. The previous studies that have yielded negative results may have been handicapped by not having a large enough exposed population to be able to unveil a true association. When researchers have worked with cohorts defined on the basis of their exposure-such as people living in corridors alongside high voltage transmission lines or cohorts selected from high density populations living close to high voltage lines-they have obtained results that are consistent and do show an association between leukaemia and exposure to magnetic fields.
1 Li CY, Thériault G, Lin RS. Epidemiological appraisal of studies of residential exposure to power frequency magnetic fields and adult cancers. Occup Environ Med 1996;53:505-10.

$2 \mathrm{Li} \mathrm{CY}$, Thériault G, Lin RS. A validity analysis of residential magnetic fields estimated from high-voltage transmission lines. Fournal of Exposure Analysis and Environmental Epidemiology 1997;7.

3 Wertheimer N, Leeper E. Electrical wiring configurations and childhood cancers. Am $\mathcal{F}$ Epidemiol 1979;109:273-84

4 Savitz DA, Wachtel H, Barnes EM, John EM, Tvrdik JG. Case-control study of childhood cancer and exposure to 60 Hz magnetic fields. Am ₹ Epidemiol 1988;128:21-38.

5 London SJ, Thomas DC, Bowman JD, Sobel E, Cheng TC, Peters JM. Exposure to residential electric and magnetic fields and risk of childhood leukeamia. $A m \mathcal{F}$ Epidemiol 1991;134:923-37.

6 Feychting M, Kaune WT, Savitz DA, Ahlbom A. Estimating exposure in studies of residential magnetic fields and cancer: importance of short-term variability, time interval between diagnosis and measurement, and distance to power line. Epidemiology 1996;7:220-4.

7 Feychting M, Ahlbom A. Magnetic fields and cancer in children residing near Swedish high-voltage power lines. $A m \mathcal{F}$ Epidemiol 1993;138:467-81.

8 Feychting M, Ahlbom A. Magnetic fields, leukaemia, and central nervous system tumors in Swedish adults residing near high-voltage power lines. Epidemiology 1994;5:501-9.

$9 \mathrm{Li} \mathrm{CY}$, Thériault GT, Lin RS. Residential exposure to $60 \mathrm{~Hz}$ magnetic fields and adult cancers in Taiwan. Epidemiology 1997;8:25-30.

10 Mantel N, Haenszel W. Statistical aspects of the analysis of data from retrospective studies of disease. $\mathcal{F}$ Natl Cancer Inst 1959;22:719-48

11 Woolf $B$. On estimating the relation between blood group and disease. Ann Hum Genet 1955;19:251-3.

12 Coleman MP, Bell CMJ, Taylor HL, Primic-Zakelj M. Leukaemia and residency near electricity transmission equipment: a case control study. Br I Cancer 1989;60:793 8.

13 Myers A, Clayden AD, Cartwright RA, Cartwright SC Childhood cancer and overhead powerlines: a case-control study. Br 7 Cancer 1990;62:1008-14.

14 Olsen $\mathrm{JH}$, Nilsen A, Schulgen G. Residence near high voltage facilities and risk of cancer in children. BMF 1993;307 891-5.

15 Verkasalo PK, Pukkala E, Hongisto MY, Valjus JE, Järvinen PJ, Heikkilä KV, Koskenvuo M. Risk of cancer in Finnish children living close to power lines. $B M M^{\prime} 1993 ; 307: 895-9$.

16 Youngson JHAM, Clayden AD, Myer A, Cartwright RA. A case/control study of adult haematological malignancies in relation to overhead powerlines. Br $\mathcal{F}$ Cancer 1991;63:97785.

17 Tynes T, Haldoren T. Electromagnetic fields and cancer in children residing near Norwegian high-voltage power lines. Am ₹ Epidemiol 1997;145:219-26.

18 Levallois P, Gauvin D, St-Laurent J, Gingras S, Deadman JE. Electric and magnetic field exposures for people living near a 735-kilovolt power line. Environ Health Perspect 1995;103:832-7. 